\title{
Identifying Indicators of Outcomes and Implementing Treatment Pathways
}

\author{
Carol Ann Huff, MD, and Jeffrey D. Dunn, PharmD, MBA
}

W ell-designed clinical trials predefine a single indicator or "endpoint" as an objective measure to indicate whether the experimental treatment or intervention provides a clinical benefit. ${ }^{1}$ Some endpoints may be surrogates or indicators that predict a real clinical outcome but do not necessarily have a guaranteed relationship with that outcome. ${ }^{1}$ Use of different endpoints in clinical trials investigating treatments for the same disease or use of surrogate endpoints that do not accurately predict the clinical benefit confounds attempts to select among competing therapies ${ }^{2,3}$ - a challenge applicable to both prescribers and managed care decision makers responsible for selecting the most efficacious and cost-effective therapies and regimens for patients with multiple myeloma enrolled in the health plan. ${ }^{4}$ This article briefly reviews indicators of clinical benefit in multiple myeloma and describes how these indicators can be used to guide decision making when selecting drug therapies for inclusion in the multiple myeloma clinical pathway.

\section{Assessing the Clinical Response in Multiple Myeloma} Historically, safe and effective treatments for patients with multiple myeloma have been limited; as a result, many promising drugs, such as melphalan, were rapidly incorporated into the treatment regimen with little understanding of the overall value of the therapy. ${ }^{5}$ However, recent approval of several new agents, including thalidomide, lenalidomide, and bortezomib, along with increased utilization of these therapies have led to efforts to quantify the value of multiple myeloma treatments and manage their use. ${ }^{6}$

\section{Indicators of Clinical Efficacy: Multiple Myeloma Clinical Trials}

Assessment of the value of a new therapy requires a standard against which to compare the novel agent. For the treatment of multiple myeloma and other cancers, the standard is prolonging survival or improving quality of life. If the effect of a new drug on survival or quality of life cannot be directly measured, a surrogate or indirect indicator of one or both of these treatment goals is often used. ${ }^{7}$ Currently, the U.S. Food and Drug Administration (FDA) considers overall survival (OS), defined as the time from randomization to an experimental arm in a clinical trial to death from any cause, to be the "gold standard" by which to evaluate new cancer therapies, including those for multiple myeloma. ${ }^{8}$ OS is precise, easy to measure, and free of bias; however, pursuing an OS endpoint in a clinical trial is time consuming and expensive and may not be required for accelerated regulatory approval. ${ }^{7}$

In 1992, the FDA began granting accelerated approval for drugs that treat serious or life-threatening diseases that have not responded to other therapies. ${ }^{9}$ Accelerated approval has been sought for both newly developed agents (e.g., bortezomib) as well as for older drugs with potentially new indications (e.g., thalidomide). Accelerated approval is often granted based on the response of surrogate indicators of clinical benefit reasonably likely to predict OS or improvement in symptoms. ${ }^{9}$ Indicators or "surrogate endpoints" recommended by the FDA as valid predictors of longer survival, improved function, or symptomatic improvement are listed in Table 1. Drugs receiving accelerated approval must undergo further testing in larger, randomized clinical trials to confirm that the drug provides the clinical benefit predicted by the surrogate. If the additional trials do not confirm the clinical benefit predicted by the surrogate, the indication is rescinded, and the drug may be removed from the market. ${ }^{9}$ Between 1992 and 2010, 35 cancer drugs, including the multiple myeloma drugs thalidomide and bortezomib, received accelerated regulatory approval for 47 new indications. ${ }^{9}$ Clinical benefit was confirmed in 26 of the $47(\sim 55 \%)$ new indications after a mean interval of 4.7 years. Clinical benefit was not confirmed in 21 accelerated indications granted between 1992 and 2010.9

During the 1970s and well into the 1980s, the FDA approved cancer drugs based on the number of patients who responded to therapy (i.e., response rate) as determined by tumor assessments from radiological tests or physical examinations. ${ }^{8,10}$ Because response rates do not reliably predict improvements in survival, quality of life, physical functioning, or tumor-related symptoms, the FDA began to move away from reliance on the response rate and adopted the position that cancer drug approval should be based on more robust evidence that treatment was providing a clinical benefit. ${ }^{8}$ By the end of the 1990s, complete response, defined as the response of several biomarkers (e.g., number of plasma cells in the bone marrow, absence of the antibody $\mathrm{M}$ protein in the blood or urine) to treatment, had become increasingly common in multiple myeloma trials. ${ }^{10,11}$ However, few patients receiving chemotherapy regimens considered standard of care a decade ago (e.g., melphalan, vincristine, cyclophosphamide) exhibited a complete response. ${ }^{12}$ In addition, concerns were raised about the ambiguity of the relationship between the biomarkers used to determine complete response and survival in patients with multiple myeloma. ${ }^{10}$

To address concerns with biomarker-based endpoints, a working group convened by the American Society of Hematology proposed using progression-free survival and time to progression as surrogates for $\mathrm{OS},{ }^{10}$ a position recently endorsed by the International Myeloma Working Group 


\section{TABLE 1 Endpoints Accepted by the FDA as Indicators of Clinical Effectiveness}

\begin{tabular}{|c|c|c|c|c|}
\hline \multirow[b]{2}{*}{ Endpoint } & \multicolumn{2}{|c|}{ Evidence } & \multirow[b]{2}{*}{ Advantage } & \multirow[b]{2}{*}{ Disadvantage } \\
\hline & Direct & Surrogate & & \\
\hline $\begin{array}{l}\text { Overall survival: } \\
\text { Time from randomization } \\
\text { until death from any cause }\end{array}$ & $\sqrt{ }$ & & $\begin{array}{l}\text { - Universally accepted } \\
\text { - Easily measured } \\
\text { - Precise }\end{array}$ & $\begin{array}{l}\text { - Can be affected by therapies administered } \\
\text { before and after experimental treatment } \\
\text { - Includes noncancer deaths }\end{array}$ \\
\hline $\begin{array}{l}\text { Symptom endpoints } \\
\text { (patient-reported } \\
\text { outcomes) }\end{array}$ & $\sqrt{ }$ & & - Provides patient perspective & $\begin{array}{l}\text { - Data often missing } \\
\text { - Clinical significance of small changes is } \\
\text { unknown } \\
\text { - Requires multiple analyses } \\
\text { - Lack of validated instruments to measure } \\
\text { changes }\end{array}$ \\
\hline $\begin{array}{l}\text { Disease-free survival: } \\
\text { Time from randomization to } \\
\text { recurrence of tumor or death } \\
\text { from any cause }\end{array}$ & & $\sqrt{ }$ & $\begin{array}{l}\text { - Shorter follow-up and smaller sample size } \\
\text { required vs. survival studies }\end{array}$ & $\begin{array}{l}\text { - Definitions vary } \\
\text { - Not precisely measured } \\
\text { - Not statistically valid as a surrogate in all } \\
\text { settings }\end{array}$ \\
\hline $\begin{array}{l}\text { Objective response rate: } \\
\text { Proportion of patients with } \\
\text { tumor size reduction of a } \\
\text { predefined amount and for } \\
\text { a minimum time period }\end{array}$ & & $\sqrt{ }$ & $\begin{array}{l}\text { - Shorter follow-up and smaller sample size } \\
\text { required vs. survival studies } \\
\text { - Effect attributable to the drug not natural } \\
\text { history of the disease }\end{array}$ & $\begin{array}{l}\text { - Not a direct measure of clinical benefit } \\
\text { - Not a comprehensive measure of drug activity } \\
\text { - Measures benefit only in the subset of patients } \\
\text { who respond }\end{array}$ \\
\hline $\begin{array}{l}\text { Complete response: } \\
\text { Elimination of detectable } \\
\text { disease }\end{array}$ & & $\sqrt{ }$ & $\begin{array}{l}\text { - Shorter follow-up and smaller sample size } \\
\text { required vs. survival studies } \\
\text { - Durable complete response can indicate } \\
\text { clinical benefit }\end{array}$ & $\begin{array}{l}\text { - Not a direct measure of clinical benefit in all } \\
\text { cases } \\
\text { - Not a comprehensive measure of drug activity } \\
\text { - Measures benefit only in the subset of patients } \\
\text { who respond }\end{array}$ \\
\hline $\begin{array}{l}\text { Progression-free survival: } \\
\text { Time from randomization to } \\
\text { objective tumor progression } \\
\text { or death }\end{array}$ & & $\sqrt{ }$ & $\begin{array}{l}\text { - Can serve as primary trial endpoints } \\
\text { - Shorter follow-up and smaller sample size } \\
\text { required vs. survival studies } \\
\text { - Includes measures of stable disease } \\
\text { - Generally based on objective/quantitative } \\
\text { assessment }\end{array}$ & $\begin{array}{l}\text { - Not valid in all settings } \\
\text { - Not precisely measured } \\
\text { - Subject to bias } \\
\text { - Definitions vary among studies }\end{array}$ \\
\hline $\begin{array}{l}\text { Time to progression: } \\
\text { Time from randomization to } \\
\text { objective tumor progression }\end{array}$ & & $\sqrt{ }$ & $\begin{array}{l}\text { - Can serve as a primary trial endpoint } \\
\text { - Shorter follow-up and smaller sample size } \\
\text { required vs. survival studies } \\
\text { - Includes measures of stable disease } \\
\text { - Generally based on objective/quantitative } \\
\text { assessment }\end{array}$ & $\begin{array}{l}\text { - Not valid in all settings } \\
\text { - Not precisely measured } \\
\text { - Subject to bias } \\
\text { - Definitions vary among studies }\end{array}$ \\
\hline
\end{tabular}

Adapted from: U.S. Department of Health and Human Services. Food and Drug Administration. Guidance for industry. Clinical trial endpoints for the approval of cancer drugs and biologics. May 2007.8

FDA =U.S. Food and Drug Administration

(IMWG) Consensus Panel $1 .{ }^{13}$ Progression-free survival is the time from start of the treatment to disease progression and is considered a surrogate marker for overall survival duration. It is also the recommended endpoint to use when describing multiple myeloma clinical trial results. ${ }^{2}$ Time to progression is the time from start of treatment to disease progression, with deaths owing to causes other than progression of multiple myeloma not counted. ${ }^{2}$ Compared with complete response, time to progression provides a more relevant assessment of treatment outcomes by providing a gauge of clinically meaningful progression in patients without the long follow-up and other concerns presented by directly measuring OS. ${ }^{14}$ Two novel multiple myeloma therapies recently received regulatory approval based on clinical benefit predicted by time to progres- sion: lenalidomide and bortezomib. However, as suggested by the accelerated FDA approvals for 21 indications granted on the basis of surrogate data but unconfirmed with further testing, clinical benefit predicted by a surrogate may not always translate into an OS benefit. ${ }^{15}$

\section{Indicators of Benefit: Clinical Practice}

Assessing response to treatment is a key determinant of multiple myeloma management in the clinic. ${ }^{16}$ To more precisely assess response to treatment at the patient level as well as to facilitate comparisons between treatment strategies, the IMWG published uniform response criteria for multiple myeloma. ${ }^{2}$ The IMWG criteria have been incorporated into the National Comprehensive Cancer Network (NCCN) clinical practice 


\section{TABLE 2 International Myeloma Working Group Uniform Response Criteria for Multiple Myeloma}

\begin{tabular}{|c|c|}
\hline Response Criteria & Definition \\
\hline Complete response (CR) & $\begin{array}{l}\text { - Negative immunofixation on the serum and urine } \\
\text { - } \leq 5 \% \text { plasma cells in bone marrow } \\
\text { - Disappearance of soft tissue plasmacytomas }\end{array}$ \\
\hline Stringent complete response (sCR) & $\begin{array}{l}\text { - CR as defined above, plus } \\
\text { - normal free light chain ratio } \\
\text { - Absence of clonal cells in bone marrow by immunohistochemistry or immunofluorescence }\end{array}$ \\
\hline Very good partial response (VGPR) & $\begin{array}{l}\text { - Serum and urine M protein detectable by immunofixation but not on electrophoresis, or } \\
\text { - } \geq 90 \% \text { reduction in serum } \mathrm{M} \text { protein level, plus } \\
\text { - Urine M protein level }<100 \mathrm{mg} \text { per } 24 \text { hours }\end{array}$ \\
\hline Partial response (PR) & $\begin{array}{l}\cdot \geq 50 \% \text { reduction of serum } \mathrm{M} \text { protein and } \\
\cdot \geq 90 \% \text { urine } \mathrm{M} \text { protein reduction or to }<200 \mathrm{mg} \text { per } 24 \text { hours and } \\
\cdot \geq 50 \% \text { decrease in soft tissue plasmacytomas }\end{array}$ \\
\hline $\begin{array}{l}\text { Stable disease (SD) } \\
\text { - Not recommended for use as an indicator of } \\
\text { response; stability of disease is best described } \\
\text { by providing the time to progression estimates }\end{array}$ & $\begin{array}{l}\text { - Not meeting criteria for CR, VGPR, PR, or progressive disease (not recommended for use as an indicator of } \\
\text { response; stability of disease is best described by providing the time-to-progression estimates) }\end{array}$ \\
\hline $\begin{array}{l}\text { Progressive disease (PD) } \\
\text { - To be used for calculation of time to } \\
\text { progression and progression-free survival and } \\
\text { points for all patients, including those in CR } \\
\text { - Includes primary progressive disease and } \\
\text { disease progression on or off therapy }\end{array}$ & $\begin{array}{l}\text { Increase of } 25 \% \text { from lowest response value in any of the following: } \\
\text { - Serum M component (absolute increase must be } \geq 0.5 \mathrm{~g} / \mathrm{dL} \text { ), and/or } \\
\text { - Urine M component (absolute increase must be } \geq 200 \mathrm{mg} \text { per } 24 \text { hours), and/or } \\
\text { - Only in patients without measurable serum and urine M protein levels; the difference between involved } \\
\text { and uninvolved free light chain levels (absolute increase must be }>10 \mathrm{mg} / \mathrm{dL} \text { ) } \\
\text { - Only in patients without measurable serum and urine } \mathrm{M} \text { protein levels and without measurable disease by } \\
\text { free light chain levels, bone marrow plasma cell PC percentage (absolute percentage must be } \geq 10 \% \text { ) } \\
\text { - Definite development of new bone lesions or soft tissue plasmacytomas or definite increase in the size of } \\
\text { existing bone lesions or soft tissue plasmacytomas } \\
\text { - Development of hypercalcemia (corrected serum calcium level }>11.5 \mathrm{mg} / \mathrm{dL} \text { ) that can be attributed solely } \\
\text { to the plasma cells proliferative disorder }\end{array}$ \\
\hline Clinical relapse & $\begin{array}{l}\text { Clinical relapse requires one or more of the following: } \\
\text { - Direct indicators of increasing disease and/or end organ dysfunction (CRAB features); it is not used in cal- } \\
\text { culation of time to or progression-free survival but is listed here as something that can be reported option- } \\
\text { ally or for use in clinical practice } \\
\text { - Development of new soft tissue plasmacytomas or bone lesions } \\
\text { - Definite increase in the size of existing plasmacytomas or bone lesions; a definite increase is defined as a } \\
50 \% \text { (and at least } 1 \mathrm{~cm} \text { ) increase as measured serially by the sum of the products of the cross-diameters of } \\
\text { the measurable lesion } \\
\text { - Hypercalcemia }(>11.5 \mathrm{mg} / \mathrm{dL} \text { ) } \\
\text { - Decrease in hemoglobin of } \geq 2 \mathrm{~g} / \mathrm{dL} \\
\text { - Increase in serum creatinine by } \geq 2 \mathrm{mg} / \mathrm{dL}\end{array}$ \\
\hline $\begin{array}{l}\text { Relapse from } \mathrm{CR}^{\mathrm{b}} \\
\text { - To be used only if the endpoint studied is } \\
\text { disease-free survival }\end{array}$ & $\begin{array}{l}\text { Any one or more of the following: } \\
\text { - Reappearance of serum or urine M protein by immunofixation or electrophoresis } \\
\text { - Development of } \geq 5 \% \text { plasma cells in the bone marrow } \\
\text { - Appearance of any other sign of progression (i.e., new plasmacytoma, lytic bone lesion, or hypercalcemia) }\end{array}$ \\
\hline
\end{tabular}

Adapted from: Durie BG, Harousseau JL, Miguel JS, et al; International Myeloma Working Group. International uniform response criteria for multiple myeloma. ${ }^{2}$

${ }^{a} C R A B$ features: hypercalcemia, renal insufficiency, anemia, and bone lesions.

${ }^{b}$ All relapse categories require 2 consecutive assessments made at any time before classification as relapse or disease progression and/or the institution of any new therapy. ${ }^{c}$ For purposes of calculating time to progression and progression-free survival, patients with $C R$ should also be evaluated using the criteria listed above for progressive disease.

$\mathrm{cm}=$ centimeter $; \mathrm{dL}=$ deciliter $\mathrm{g}=$ gram; $m g=$ milligram .

guidelines for multiple myeloma and include the following: complete response, stringent complete response, very good partial response, partial response, stable disease, progressive disease, clinical response, and relapse from clinical response (Table 2). Each response criterion is defined by specific biochemical changes occurring in response to treatment, which are described in detail elsewhere. ${ }^{2,13}$

\section{Therapeutic Decision Making in Multiple Myeloma Multiple Myeloma Treatment Overview}

Multiple myeloma typically follows a relapsing course, with the clinical benefit of treatment decreasing with each subsequent line of therapy. ${ }^{17}$ In the absence of definitive cure, the goal of treatment is to improve patients' long-term outcomes, including prolonging progression-free survival and OS. ${ }^{17}$ Therapeutic selection is influenced by the patient's overall 


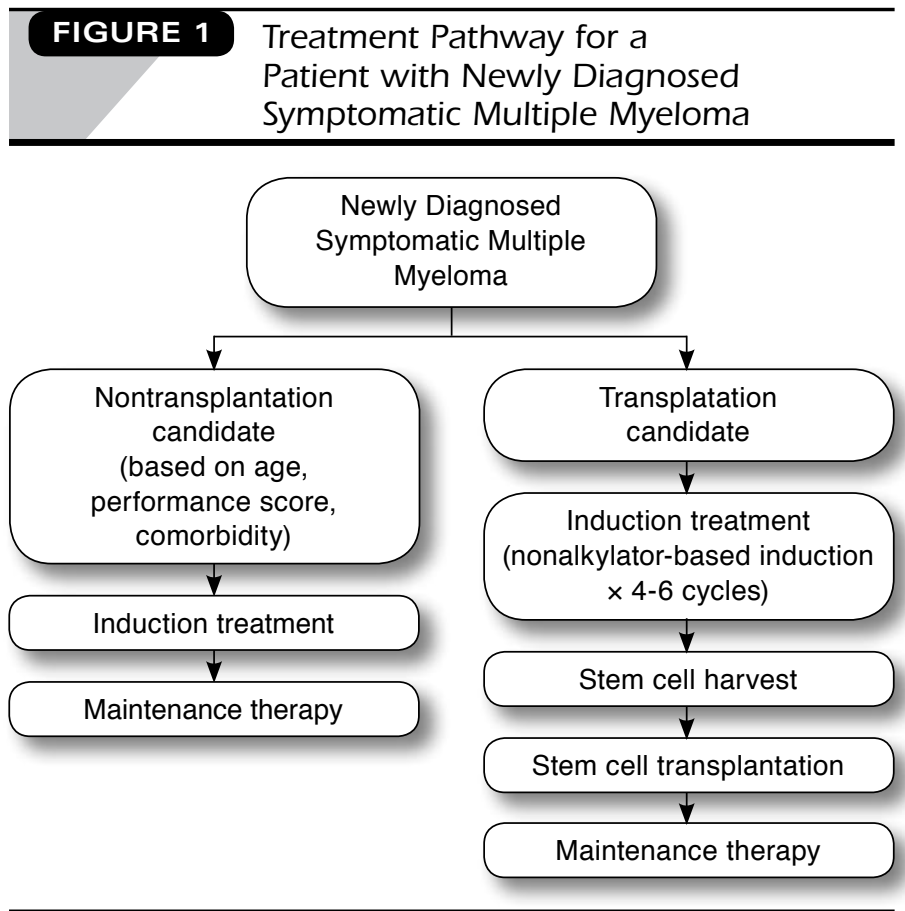

Adapted from: Rajkumar SV. Multiple myeloma: 2012 update on diagnosis, riskstratification, and management. ${ }^{20}$

health, age, prior therapy, and the presence of symptoms, comorbidities, and/or disease complications. ${ }^{16} \mathrm{Up}$ to $25 \%$ of patients present with asymptomatic disease and may remain stable for 10 to 15 years. ${ }^{18}$ In these patients, treatment is typically withheld until the patient develops active or symptomatic myeloma because early intervention has not been shown to affect survival. ${ }^{19}$

Treatment of symptomatic patients generally follows a 2-step approach: a relatively short period of initial (or induction) therapy followed by a longer maintenance phase (Figure 1). ${ }^{20}$ The primary options for therapy include standard chemotherapy such as melphalan, cyclophosphamide, doxorubicin, and liposomal doxorubicin; corticosteroids such as dexamethasone and prednisone; newer drugs such as thalidomide, lenalidomide, and bortezomib; and stem cell transplantation. ${ }^{16}$ The NCCN recommends induction (i.e., initial) therapy with thalidomide, lenalidomide, or bortezomib plus autologous stem cell transplantation (ASCT) for younger patients (generally younger than 75 years of age) who present without comorbid heart, lung, renal, or liver disease (Table 3). ${ }^{16}$ Use of alkylating therapies such as platinum chemotherapies in the induction phase should be limited to avoid compromising stem cell reserve before stem cell harvest in transplant-eligible patients. ${ }^{20}$ Various combinations of melphalan, dexamethasone, and prednisone with thalidomide, lenalidomide, or bortezomib are recommended for patients ineligible for trans- plant due to significant systemic comorbidities or advanced age (generally older than 75 years). ${ }^{21}$ Once the best remission has been achieved, the induction phase should be followed by maintenance therapy with lenalidomide or thalidomide, with or without corticosteroids, which can prolong remission but not survival. ${ }^{16} \mathrm{~A}$ third phase of treatment, salvage therapy, may be initiated in patients who experience a relapse following a stem cell transplant or in patients with primary progressive disease following an initial transplant. ${ }^{16}$ Salvage therapy can also be used in patients who are ineligible for a stem cell transplant with progressive or relapsing disease after initial induction therapy. If a sustained remission was obtained with initial therapy, then consideration should be given to using it again. ${ }^{16}$ Salvage regimens recommended by the NCCN are listed in Table 3.

\section{Clinical Indicators and Treatment Selection}

One important factor widely associated with improved progression-free survival and OS in multiple myeloma is the quality of response to treatment and, in particular, the achievement of a durable complete response. Complete response represents elimination of detectable disease by currently available laboratory methods. ${ }^{11}$ Many oncologists believe complete response is a good surrogate for survival and the key to long-term disease control because several studies suggest that complete response is correlated with survival. ${ }^{22,23}$ However, achievement of complete response is highly dependent on the treatment regimen; complete response was not common with conventional chemotherapy such as melphalan and prednisone or vincristine, doxorubicin, and dexamethasone. ${ }^{12}$ Although these regimens demonstrated antimyeloma activity in more than half of patients, treatment was generally not sufficiently intensive to eliminate all traces of disease. ${ }^{24}$ The value of complete response as a valid surrogate of clinical benefit did not become evident until the introduction of treatment regimens that used highdose chemotherapy (HDT) in the initial or induction phase of treatment followed by ASCT. ${ }^{11,25}$ Compared with conventional chemotherapeutic regimens, HDT followed by stem cell transplant increased complete response rates to as high as 50\%, and this was associated with longer progression-free survival and OS in most randomized studies. ${ }^{26}$ High complete response rates have also been observed in patients treated with lenalidomide, thalidomide, and bortezomib compared with those receiving conventional chemotherapeutic regimens. ${ }^{27}$ At this point in time, the evidence suggests that lenalidomide, thalidomide, and bortezomib are associated with improved OS from the time of diagnosis ${ }^{28,29}$ as well as delaying the time to relapse. ${ }^{30}$

It is important to note that responses reported as complete response in the literature are not necessarily uniform and may therefore represent different levels of disease control based on the criteria used in the study. ${ }^{24}$ For example, the duration of the complete response may be a stronger predictor of OS 


\section{TABLE 3 Multiple Myeloma Therapies}

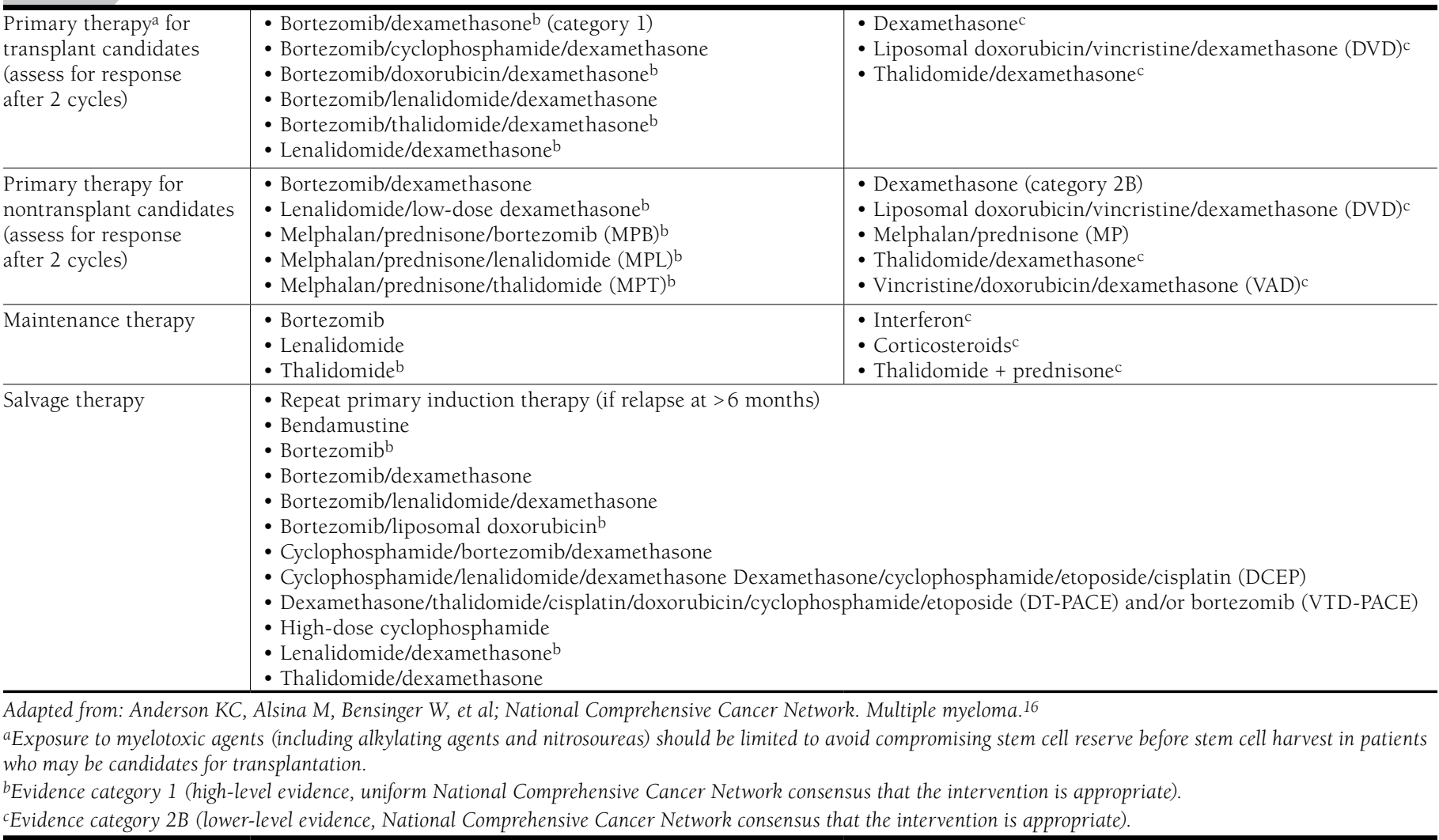

than simply achieving a complete response at some point in time. ${ }^{31}$ Additionally, although obtaining a durable complete response is associated with statistically significant longer OS in the majority of patients with multiple myeloma, there are some subgroups in which the relationship between complete response and OS is questionable, including rapidly-responding but early-relapsing patients, those with more indolent (i.e., slowly progressing) disease, and those with stable nonprogressive disease after induction therapy. ${ }^{18}$

The quality or depth of the complete response is another factor that appears to be associated with prolonged progressionfree survival and OS. ${ }^{32,33}$ The depth of the complete response is defined by quantitative and qualitative changes in diseaserelated biomarkers as a result of treatment. Increasingly sensitive analytic techniques are now being explored to define more stringent degrees of complete response or elimination of minimal residual disease, including multiparameter flow cytometry and polymerase chain reaction. ${ }^{24}$ Demonstrating eradication of minimal residual disease by these techniques has been shown to predict improved outcomes. High rates of complete response have been reported following consolidation therapy with novel agent-based regimens (i.e., a short course of treatment utilized to deepen the response achieved with induction therapy) ${ }^{32,34}$ Use of these agents in the maintenance phase has also improved depth of response, delayed time to progression, and improved outcomes ${ }^{35-38}$ in younger and elderly patients. ${ }^{39-41}$

Given the evidence arising from the clinical literature, complete response is now recognized as a surrogate for OS and as a clinically relevant endpoint in multiple myeloma studies. ${ }^{10}$ Complete response can also be considered an important therapeutic goal at all stages of treatment, and its routine measurement can be used to guide therapeutic interventions and assess response to therapy. ${ }^{10}$ It is important to note, however, that questions remain regarding complete response, and these questions may have implications on patient management. For example, it is not clear if all complete responses are equal in terms of depth of response and prognostic importance (i.e., whether complete response after HDT-ASCT is necessarily the equivalent of complete response achieved with nonintensive chemotherapy or with novel agent-based regimens). Answers to this and other questions await future investigation. ${ }^{24}$

\section{- Clinical Pathways and the Management of Multiple Myeloma}

Multiple myeloma represents a small percentage of all cancers treated in an oncology practice, but its associated clinical and 
financial burden is disproportionately high. ${ }^{6}$ Of all cancers that affect the skeletal system, either as a primary tumor or due to metastatic disease, multiple myeloma had the highest mean cost per patient at $\$ 132,615$, compared with $\$ 88,402$ and $\$ 65,287$ for patients with breast or lung cancer, respectively, who developed metastatic bone disease. ${ }^{42}$ The growing cost of multiple myeloma care is being felt by all stakeholders, including payers, prescribers, and patients. Consequently, payers are increasingly focusing resources on managing costs while simultaneously providing patient access to treatment. ${ }^{43}$ One key to controlling costs in oncology is to influence the prescribing process. ${ }^{44}$ Although both private and governmental payers are developing and implementing processes to influence prescribing patterns, collaboration between payers and prescribers is critical for long-term success of the management program. ${ }^{44,45}$ Although individual management strategies vary among payers, one increasingly common approach is to work with oncology providers to establish clinical pathways or management plans for multiple myeloma and other cancers. ${ }^{44}$ At the most fundamental level, clinical pathways represent an agreement by oncologists to treat a patient with multiple myeloma in a certain way. Clinical pathways are a tool to standardize care, decrease resource utilization, and improve clinical outcomes as measured by accepted criteria such as complete response. ${ }^{43,45} \mathrm{~A}$ clinical pathway may also provide a framework in which new therapies and treatment regimens can be evaluated and provide a mechanism to improve communication and create shared ownership of treatment outcomes. ${ }^{44}$

\section{Developing a Clinical Pathway}

A clinical pathway is devised and implemented by a group of oncologists in collaboration with a health plan. ${ }^{46}$ Oncologists are primarily responsible for reviewing the current clinical evidence and, based on clinical outcomes, safety, tolerability, and convenience of dosing and administration, determine the most appropriate treatment. The value of the selected therapeutic interventions (i.e., for multiple myeloma, pharmacologic intervention as well as stem cell transplant), defined as clinical outcomes divided by costs, is also considered. The pathway is adopted by the oncology practice and operationally implemented; compliance is documented; and retrospective data monitoring is conducted to assess pathway appropriateness and accountability. ${ }^{46}$ The clinical pathway is reviewed at regular intervals to incorporate newly released data and account for any change in practice standards. ${ }^{46}$ Payers also have a role: the payer provides an incentive that encourages the oncology providers to comply with the clinical pathway. ${ }^{44}$ This incentive should not represent the potential to break even, but rather to gain. The decision to not participate or comply with the clinical pathway cannot place the provider at a disadvantage compared with a colleague who is reimbursed based on a standard fee schedule. On the contrary, compliance with the clinical pathway should result in a gain above the nonparticipatory rate. ${ }^{44}$

\section{Clinical Pathways in Multiple Myeloma}

Clinical pathways have become established for the most common solid tumors. The number of individual practices that are using clinical pathways in oncology is unknown but growing, and the scope of clinical pathways varies across the payer landscape. ${ }^{47}$ For example, Via Oncology, a subsidiary of the University of Pittsburgh Medical Center, has pathways that cover 17 types of cancer and include prognostic testing, chemotherapy and biologic therapy, supportive care, and radiation therapy. In contrast, BlueCross BlueShield of Michigan has instituted 3 regimens for treating patients with adjuvant low-risk breast cancer. ${ }^{47}$ Among payers who adopted clinical pathway programs, breast cancer (83\%) was the most common of the oncology subtypes, followed by lung (70\%), colon/rectal (60\%), multiple myeloma (43\%), prostate (40\%), kidney (38\%), ovarian (38\%), chronic lymphocytic leukemia (35\%), liver (33\%), and melanoma (30\%). ${ }^{48}$ CareFirst BlueCross BlueShield, which serves the Mid-Atlantic region, was one of the first payers to implement a clinical pathway for multiple myeloma. ${ }^{44}$ Since its introduction in 2010, physician compliance with the pathway has increased to approximately $90 \%$. Although additional data on the impact of the pathway on clinical outcomes and cost savings are not available at the current time, use of a similar pathway to guide treatment of breast, lung, and colon cancers resulted in a $10 \%$ reduction in the number of regimens utilized to treat these diseases as well as a gross savings to the health plan of $13 \%$ to $14 \%$ when financial trends in the participating group of patients were compared with those in the nonparticipating group. ${ }^{44}$

\section{Clinical Pathways and Treatment Guidelines}

As therapeutic options for patients with multiple myeloma have increased, uncertainty has arisen about the optimal approach to therapy. ${ }^{18}$ Clinical practice guidelines published and regularly updated by the NCCN can guide therapeutic decision making for patients with multiple myeloma. These guidelines are considered the "gold standard" because they stratify treatment recommendations based on the strength of the clinical evidence and expert consensus where objective data are lacking. These guidelines describe the universe of treatment options in multiple myeloma and form a foundation for therapeutic decision making embraced by both oncologists and payers. However, multiple drugs and regimens receive the same recommendation, and thus, the guidelines provide little guidance on which treatment options offer the best combination of safety, tolerability, and clinical benefit. ${ }^{16}$ Clinical pathways bridge the gap between broad treatment recommendations provided by the 
NCCN guidelines and the specific actionable steps for oncologists to consult and from which to create an individualized patient management plan. Well-designed clinical pathways incorporated into an electronic medical record system can also allow providers to review multiple peer-recommended options based on diagnosis, stage, and progression accompanied by the associated literature citations. ${ }^{49}$ Furthermore, pathways based on evidence-based treatment guidelines can provide consistency in treatment and predictability, both of which are of significant interest to payers. ${ }^{49}$

\section{Summary}

Well-designed clinical trials predefine a single indicator or endpoint as an objective measure to indicate whether the experimental intervention provides a clinical benefit. OS is considered the gold standard endpoint, but it is not always measured. When OS is unavailable, surrogate endpoints are relied on to predict the ultimate clinical outcome. Common surrogates for OS include progression-free survival and time to progression. With the advent of more effective therapies, complete response, a surrogate that had its usefulness questioned because of ambiguity in the relationship between the biomarkers used to assess complete response and clinical benefit, has re-emerged and is now widely used both as a clinical and an investigative tool to assess the depth and duration of a clinical response. Evidence gained from the use of these clinical indicators has been incorporated into clinical practice guidelines such as those published by the NCCN. Treatment recommendations contained within the guidelines form the foundation of clinical pathways used by many providers and payers to guide the treatment of patients with cancer. Although data are not yet available to determine this with any certainty, it is believed that use of clinical pathways in the treatment of patients with multiple myeloma will standardize care, decrease resource utilization, and improve clinical outcomes.

\section{Authors}

CAROL ANN HUFF, MD, is Associate Professor of Oncology and Medicine and Director of the Multiple Myeloma Program in the Division of Hematology Malignancies, Johns Hopkins University School of Medicine, Baltimore, Maryland; and JEFFREY D. DUNN, PharmD, MBA, is Formulary and Contract Manager, SelectHealth, Salt Lake City, Utah.

AUTHOR CORRESPONDENCE: Carol Ann Huff, MD, Sidney Kimmel Comprehensive Cancer Center at Johns Hopkins Hospital, 401 N. Broadway, Baltimore, MD 21231. Tel: 443.287.7104; Fax: 410.502.7213; E-mail: huffca@jhmi.edu.

\section{REFERENCES}

1. Johnson JR, Williams G, Pazdur R. End points and United States Food and Drug Administration approval of oncology drugs. J Clin Oncol. 2003;21(7):1404-11.

2. Durie BG, Harousseau JL, Miguel JS, et al. International uniform response criteria for multiple myeloma. Leukemia. 2006;20(9):1467-73.

3. Rajkumar SV, Gahrton G, Bergsagel PL. Approach to the treatment of multiple myeloma: a clash of philosophies. Blood. 2011;118(12):3205-11.

4. Kenney JT, Mauro M, Yee G. New endpoints create novel challenges for health plans in oncology drug management. Value-Based Cancer Care. 2011;2(4):50-55. Available at: http://www.valuebasedcancer.com/ myeloma/article/importance-clinical-end-points-multiple-myelomapayer\%E2\%80\%99s-perspective. Accessed October 19, 2012.

5. Kyle RA, Rajkumar SV. Multiple myeloma. Blood. 2008;111(6):2962-72.

6. Cook R. Economic and clinical impact of multiple myeloma to managed care. J Manag Care Pharm. 2008;14(7 Suppl):S19-S25. Available at: http:// www.amcp.org/data/jmcp/Sept08\%20Suppl_S19-S25.pdf.

7. McKee AE, Farrell AT, Pazdur R, Woodcock J. The role of the U.S. Food and Drug Administration review process: clinical trial endpoints in oncology. Oncologist. 2010;15(Suppl 1):S13-S18.

8. U.S. Department of Health and Human Services. Food and Drug Administration. Guidance for industry. Clinical trial endpoints for the approval of cancer drugs and biologics. May 2007. Available at: http://www. fda.gov/downloads/Drugs/GuidanceComplianceRegulatoryInformation/ Guidances/UCM071590. Accessed October 19, 2012

9. Johnson JR, Ning YM, Farell A, Keegan P, Pazdur R. Accelerated approval of oncology products: the Food and Drug Administration experience. J Natl Cancer Inst. 2011;103(8):636-38.

10. Anderson KC, Kyle RA, Rajkumar SV, et al. Clinically relevant end points and new drug approvals for myeloma. Leukemia. 2008;22(2):231-39.

11. Harousseau JL, Attal M, Avet-Loiseau H. The role of complete response in multiple myeloma. Blood. 2009;114(15):3139-46

12. Durie BG, Jacobson J, Barlogie B, Crowley J. Magnitude of response with myeloma frontline therapy does not predict outcome: importance of time to progression in Southwest Oncology Group chemotherapy trials. J Clin Oncol. 2004;22(10):1857-63.

13. Rajkumar SV, Harousseau JL, Durie B, et al; International Myeloma Workshop Consensus Panel 1. Consensus recommendations for the uniform reporting of clinical trials: report of the International Myeloma Workshop Consensus Panel 1. Blood. 2011;117(18):4691-95.

14. Kane RC, Bross PF, Farrell AT, Pazdur R. Velcade: U.S. FDA approval for the treatment of multiple myeloma progressing on prior therapy. Oncologist. 2003;8(6):508-13

15. Richey EA, Lyons EA, Nebeker JR, et al. Accelerated approval of cancer drugs: improved access to therapeutic breakthroughs or early release of unsafe and ineffective drugs? J Clin Oncol. 2009;27(26):4398-405.

16. Anderson KC, Alsina M, Bensinger W, et al; National Comprehensive Cancer Network. Multiple myeloma. J Natl Compr Canc Netw. 2011;9(10): 1146-83.

17. Kumar SK, Therneau TM, Gertz MA, et al. Clinical course of patients with relapsed multiple myeloma. Mayo Clin Proc. 2004;79(7):867-74.

18. Stewart AK, Richardson PG, San-Miguel JF. How I treat multiple myeloma in younger patients. Blood. 2009;114(27):5436-43.

19. Dimopoulos MA, Terpos E. Multiple myeloma. Ann Oncol. 2010;21(Suppl 7): S143-S150

20. Rajkumar SV. Multiple myeloma: 2012 update on diagnosis, risk-stratification, and management. Am J Hematol. 2012;87(1):78-88. 
21. Palumbo A, Sezer O, Kyle R, et al. International Myeloma Working Group guidelines for the management of multiple myeloma patients ineligible for standard high-dose chemotherapy with autologous stem cell transplantation. Leukemia. 2009;23(10):1716-30.

22. San Miguel JF, Schlag R, Khuageva NK, et al. Bortezomib plus melphalan and prednisone for initial treatment of multiple myeloma. N Engl J Med. 2008;359(9):906-17.

23. Richardson PG, Sonneveld P, Schuster M, et al. Bortezomib or highdose dexamethasone for relapsed multiple myeloma. N Engl J Med. 2005;352(24):2487-98.

24. Chanan-Khan AA, Giralt S. Importance of achieving a complete response in multiple myeloma, and the impact of novel agents. J Clin Oncol. 2010;28(15):2612-24

25. Barlogie B, Jagannath S, Vesole DH, et al. Superiority of tandem autologous transplantation over standard therapy for previously untreated multiple myeloma. Blood. 1997;89(13):789-93.

26. Niesvizky R, Richardson PG, Rajkumar SV, et al. The relationship between quality of response and clinical benefit for patients treated on the bortezomib bortezomib arm of the international, randomized, phase 3 APEX trial in relapsed multiple myeloma. Br J Haematol. 2008;143(1):46-53.

27. Harousseau JL, Dimopoulos MA, Wang M, et al. Better quality of response to lenalidomide plus dexamethasone is associated with improved clinical outcomes in patients with relapsed or refractory multiple myeloma. Haematologica. 2010;95(10):1738-44.

28. Brenner H, Gondos A, Pulte D. Recent major improvement in long-term survival of younger patients with multiple myeloma. Blood. 2008;111(5):2521-26

29. Kumar SK, Rajkumar SV, Dispenzieri A, et al. Improved survival in multiple myeloma and the impact of novel therapies. Blood. 2008;111(5):2516-20.

30. Richardson PG, Mitsiades C, Schlossman R, et al. New drugs for myeloma. Oncologist. 2007;12(6):664-89.

31. Pineda-Roman M, Bolejack V, Arzoumanian V, et al. Complete response in myeloma extends survival without, but not with history of prior monoclonal gammopathy of undetermined significance or smouldering disease. Br J Haematol. 2007;136(3):393-99.

32. Lahuerta JJ, Mateos MV, Martínez-López J, et al. Influence of preand post-transplantation responses on outcome of patients with multiple myeloma: sequential improvement of response and achievement of complete response are associated with longer survival. J Clin Oncol. 2008;26(35):5775-82

33. van de Velde HJ, Liu X, Chen G, Cakana A, Deraedt W, Bayssas M. Complete response correlates with long-term survival and progressionfree survival in high-dose therapy in multiple myeloma. Haematologica. 2007;92(10):1399-406

34. Palumbo A, Gay F, Falco P, et al. Bortezomib as induction before autologous transplantation, followed by lenalidomide as consolidation-maintenance in untreated multiple myeloma patients. J Clin Oncol. 2010;28(5):800-07.
35. Attal M, Harousseau JL, Leyvraz S, et al. Maintenance therapy with thalidomide improves survival in patients with multiple myeloma. Blood. 2006;108(10):3289-94

36. Spencer A, Prince HM, Roberts AW, et al. Consolidation therapy with low-dose thalidomide and prednisolone prolongs the survival of multiple myeloma patients undergoing a single autologous stem-cell transplantation procedure. J Clin Oncol. 2009;27(11):1788-93.

37. Barlogie B, Tricot G, Anaissie E, et al. Thalidomide and hematopoietic-cell transplantation for multiple myeloma. N Engl J Med. 2006;354(10):1021-30.

38. Ludwig H, Adam Z, Tóthová E, et al. Thalidomide maintenance treatment increases progression-free but not overall survival in elderly patients with myeloma. Haematologica. 2010;95(9):1548-54

39. Attal M, Lauwers-Cances V, Marit G, et al; IFM Investigators. Lenalidomide maintenance after stem-cell transplantation for multiple myeloma. N Engl J Med. 2012;366(19):1782-91.

40. McCarthy PL, Owzar K, Hofmeister CC, et al. Lenalidomide after stem-cell transplantation for multiple myeloma. N Engl J Med. 2012;366(19):1770-781.

41. Palumbo A, Hajek R, Delforge M, et al; MM-015 Investigators. Continuous lenalidomide treatment for newly diagnosed multiple myeloma. N Engl J Med. 2012;366(19):1759-69.

42. Schulman KL, Kohles J. Economic burden of metastatic bone disease in the U.S. Cancer. 2007;109(11):2334-42.

43. Chitre M. An integrated approach for managing oncology drug therapies: dose efficiency and other initiatives for multiple myeloma. Manag Care Oncol 2011;3:15-18. Available at: http://managedcareoncology.com/media/416971/ web_q3_final.pdf. Accessed October 19, 2012.

44. Wong W. Are pathways an effective tool for controlling costs? Valuebased care in myeloma. January 2012. Available at: http://www.valuebasedcancer.com/myeloma/article/are-pathways-effective-tool-controlling-costs. Accessed October 19, 2012

45. Feinberg BA, Lang J, Grzegorczyk J, et al. Implementation of cancer clinical care pathways: a successful model of collaboration between payers and providers. J Oncol Pract. 2012;8(3 Suppl):e38s-43s.

46. Cutter B. Putting multiple myeloma on the clinical pathway. Value-Based Cancer Care. 2010;1(4):24. Available at: http://www.coexm.com/sites/default/ files/LSYMP710.pdf. Accessed October 19, 2012.

47. Gesme DH, Wiseman M. Strategic use of clinical pathways. J Oncol Pract. 2011;7(1):54-56

48. Goldberg L, Snyder M. New control techniques on the horizon for payer oncology management. The Zitter Group. 2012. Available at: http://www. zitter.com/Newsletter/downloads/New\%20Control\%20Techniques\%20 on\%20the\%20Horizon\%20for\%20Payer\%20Oncology\%20Management.pdf. Accessed October 19, 2012

49. Sullivan WJ. Demystifying pathways in oncology. Manag Care. 2012;21(6):34-38. Available at: http://www.managedcaremag.com/ archives/1206/1206.oncologypathways.html. Accessed October 19, 2012. 